\title{
Common features of atopic dermatitis with hypoproteinemia
}

So Yoon Jo, MD, Chan-Ho Lee, MD, Woo-Jin Jung, MD, Sung-Won Kim, MD, PhD, Yoon-Ha Hwang, MD

Department of Pediatrics, Busan St. Mary's Hospital, Busan, Korea

Purpose: The purpose of this study was to identify the causes, symptoms, and complications of hypoproteinemia to prevent hypoproteinemia and provide appropriate treatment to children with atopic dermatitis.

Methods: Children diagnosed with atopic dermatitis with hypoproteinemia and/or hypoalbuminemia were retrospectively reviewed. The patients' medical records, including family history, weight, symptoms, treatment, complications, and laboratory test results for allergies and skin cultures, were examined.

Results: Twenty-six patients ( 24 boys) were enrolled. Seven cases had growth retardation; 7 , keratoconjunctivitis; 6 , aural discharges; 5, eczema herpeticum; 4, gastrointestinal tract symptoms; and 2, developmental delays. In 21 cases, topical steroids were not used. According to the blood test results, the median values of each parameter were elevated: total lgE, 1,864 U/mL; egg white-specific lgE, $76.5 \mathrm{kU}_{\mathrm{A}} /$

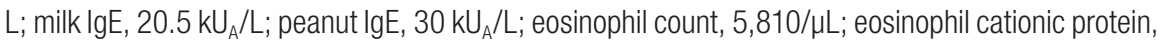
$93.45 \mu \mathrm{g} / \mathrm{L}$; and platelet count, $666.5 \times 10^{3} / \mathrm{LL}$. Serum albumin and total protein levels decreased to 2.7 $\mathrm{g} / \mathrm{dL}$ and $4.25 \mathrm{~g} / \mathrm{dL}$, respectively. Regarding electrolyte abnormality, 10 patients had hyponatremia, and 12, hyperkalemia. Systemic antibiotics were used to treat all cases, and an antiviral agent was used in 12 patients. Electrolyte correction was performed in 8 patients.

Conclusion: Hypoproteinemia accompanying atopic dermatitis is common in infants younger than 1 year and may occur because of topical steroid treatment continuously being declined or because of eczema herpeticum. It may be accompanied by growth retardation, keratoconjunctivitis, aural discharge, and eczema herpeticum and can be managed through skin care and topical steroid application without intravenous albumin infusion.

Key words: Atopic dermatitis, Hypoproteinemia, Hypoalbuminemia

\section{Introduction}

Since its first introduction in 1986, cases of atopic dermatitis with hypoproteinemia have been consistently reported. ${ }^{1)}$ In a previous study, patients with atopic dermatitis with hypoproteinemia had high SCORing Atopic Dermatitis (SCORAD) indices, a high total IgE, sensitization to various foods, and early sensitization to Dermatophagoides pteronyssinus (Dp). ${ }^{2)}$ Similar case studies have been reported worldwide, including Korea and Japan; however, most of studies have only reviewed a limited number of cases. ${ }^{3)}$

Atopic dermatitis usually occurs in young children and is commonly accompanied with dehydration, electrolyte imbalance, growth or developmental retardation, and severe food allergies. However, common features of atopic dermatitis with hypoproteinemia cannot be easily determined because only a few cases have been reported. Hence, we aimed to investigate the common features of atopic dermatitis with hypoproteinemia based on the cases we encountered over 10 years at a single center.
Corresponding author: So Yoon Jo, MD

Department of Pediatrics, Busan St. Mary's Hospital, 25-14 Yongho-ro 232gil, Nam-gu, Busan 48575 , Korea

Tel: +82-51-933-7114

Fax: +82-51-932-8600

E-mail: whthdbs1220@naver.com

https://orcid.org/0000-0001-6292-1495

Received: 7 February, 2018

Revised: 1 July, 2018

Accepted: 6 July, 2018
Copyright (C) 2018 by The Korean Pediatric Society

This is an open-access article distributed under the terms of the Creative Commons Attribution NonCommercial License (http://creativecommons.org/ licenses/by-nc/4.0/) which permits unrestricted noncommercial use, distribution, and reproduction in any medium, provided the original work is properly cited. 


\section{Materials and methods}

\section{Participants}

Among the patients diagnosed with atopic dermatitis at the Department of Pediatrics at Busan St. Mary's Hospital between June 2006 and May 2017, 26 patients who also had a blood albumin concentration of $<3.5 \mathrm{~g} / \mathrm{dL}$ were enrolled in this study. Atopic dermatitis was diagnosed based on the criteria suggested by Hanifin and Rajka in 1980."

For disease history, we investigated patients' sex, age, weight, delivery method, digestive symptoms (e.g., vomiting and diarrhea), growth or developmental delays, topical steroid use, and length of hospital stay, as well as the parents' allergies (allergic rhinitis, bronchial asthma, allergic conjunctivitis, contact allergy, food allergy, and anaphylaxis).

Patients were also examined for impetigo, eczema herpeticum, aural discharge, blepharitis, and their SCORAD index. To ensure objectivity, a specialist in pediatric allergy and respiratory diseases assessed the SCORAD index through examining the photographs stored in the patient's electronic chart. Eczema herpeticum was diagnosed in consultation with a dermatology specialist based on disseminated vesicles, pustules, erosions on the face and other parts of the body, punched-out lesions, or according to the Tzanck test or herpes simplex virus polymerase chain reaction results.

A blood test was performed to obtain a complete blood count with a differential count (white blood cell [WBC], eosinophil, and platelet counts) and the erythrocyte sedimentation rate, as well as concentrations of C-reactive protein (CRP), eosinophil cationic protein (ECP), total protein, serum albumin, and electrolytes (sodium, potassium, and chloride).

The peripheral blood eosinophil count was measured using an ADVIA 120 (Bayer, Leverkusen, Germany) automated hematology analyzer. To measure ECP, the blood sample was incubated in a serum separation tube (Becton Dickinson, Franklin Lakes, NJ, USA) at room temperature for 1 hour, and the ImmunoCAP system was used to perform the fluoroimmunoassay.

Total and specific IgE (ImmunoCAP, Pharmacia Diagnostics $\mathrm{AB}$, Uppsala, Sweden) for egg white, milk, peanuts, and Dp were measured.

In addition to blood sampling, a staff member of the pediatrics department collected a sample from each patient's inflamed skin lesions and exudates while wearing gloves, inserted the swab in the transfer media, and delivered it to the laboratory. After inoculating the sample on a blood agar plate, it was incubated for 24 hours in $3 \%-5 \% \mathrm{CO}_{2}$ at $35^{\circ} \mathrm{C}$. When characteristic colonies were observed, catalase and coagulase tests were performed to confirm the presence of Staphylococcus aureus; alternatively, VITEC 2 (Biomériusinc, Durham, NC, USA) was used to identify the bacteria.

For body weight, patients' percentiles were computed with reference to the 2007 standard growth chart for children and adole- scents.

Regarding treatment, patients' data were reviewed to determine whether topical steroid therapy, antibiotic therapy, antiviral agents (acyclovir), intravenous (IV) albumin, and electrolyte control should be administered.

\section{Statistical analysis}

Data were presented as means \pm standard deviations and medians (range). Categorical data were compared using the chi-square test, and continuous data were compared using the Mann-Whitney and Kruskal-Wallis tests. Statistical significance was set at $P<0.05$. All calculations were performed using SPSS ver. 14.0 (SPSS Inc., Chicago, IL, USA).

This study was approved by the Institutional Review Board at Busan St. Mary's Hospital (approval number: BSM 2017-13).

\section{Results}

Of 26 participants, 24 (92.3\%) were boys with a median age of 7 months (range, 3-14 months), and were not significantly associated with birth weight (median, $3.27 \mathrm{~kg}$ ) and cesarean delivery (30.8\%). The age of onset was mostly <1 year (92.3\%). Only 2 patients (7.7\%) developed the condition after 12 months of age; however, the age difference was not significant (13 and 14 months, respectively). The median weight at admission was $7.55 \mathrm{~kg}$ (range, 5.2-11.5 kg), and 7 patients (26.9\%) had growth retardation below the 3rd percentile; the remaining patients were within the normal weight range (Fig. 1). A total of 14 fathers (53.8\%) and 14 mothers (53.8\%) had allergies. Four patients (15.4\%) had digestive symptoms such as vomiting or diarrhea, 2 (7.7\%) had developmental disorders, 7 (26.9\%) presented with a failure to thrive, 6 (23.1\%) had otitis externa, and 7 (26.9\%) had blepharitis and conjunctivitis. Five patients (19.2\%) had eczema herpeticum. Regarding serious complications, 1 patient had ecthymagangrenosum and 1 had acute renal failure. All patients had a severe condition, with a SCORAD index of >40 (median, 48.3;

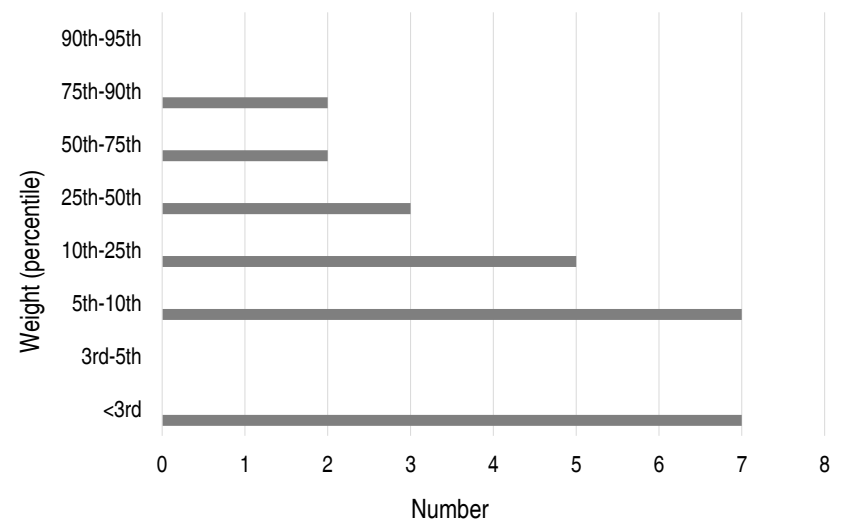

Fig. 1. Distribution of body weight percentiles. 
Table 1. Patient characteristics

\begin{tabular}{lc}
\hline Characteristic & Value \\
\hline Male sex & $24(92.3)$ \\
Age (yr) & $7(3-14)$ \\
Ceserean section & $8(30.8)$ \\
Birth weight (kg) & $3.27(2.3-4.3)$ \\
Weight (kg) & $7.55(5.2-11.5)$ \\
Family history ${ }^{\star}$ & \\
Father & $8(30.8)$ \\
Mother & $8(30.8)$ \\
Both & $6(23.1)$ \\
Comorbid illness & \\
Developmental disorder & $2(7.7)$ \\
Growth failure & $7(26.9)$ \\
Eczema herpeticum & $5(19.2)$ \\
Gastrointestinal symptoms ${ }^{\dagger}$ & $4(15.4)$ \\
Otorrhea & $6(23.1)$ \\
Blepharoconjunctivitis & $7(26.9)$ \\
Ecthymagangrenosum & $1(3.8)$ \\
Acute renal failure & $1(3.8)$ \\
SCORAD (score) & $48.3(41.1-83.0)$ \\
\hline
\end{tabular}

Values are presented as number (\%) or mean (range).

SCORAD, SCORing Atopic Dermatitis.

*If any of following allergic diseases (bronchial asthma, allergic rhinitis, atopic dermatitis, food allergy, allergic contact dermatitis, allergic conjunctivitis, or anaphylaxis) are present, the family history is considered positive. 'Vomiting and diarrhea. range, 41.1-83.0) (Table 1).

In this study, we examined declining both the use of topical steroids and eczema herpeticum as 2 predisposing factors of hypoproteinemia. In 21 patients (80.8\%), topical steroids had not been used. These patients had been treated with folk medicine ( $n=13,50.0 \%)$ and traditional Korean medical treatments $(n=8,30.8 \%)$ instead of the standard treatment (topical steroids). The patients' conditions progressed to severe atopic dermatitis due to a prolonged period declining the use of topical steroids, defined as the delayed application of steroids from the time of diagnosis for a period of 6 months or longer, before being admitted to hospital. Folk therapies and traditional Korean medicines included wind bathing, detoxification, natural soap, acidic water, aloe, Siberian cocklebur, and vitamins. Five patients (19.2\%) had eczema herpeticum; with 4 of them (15.4\%) having developed eczema herpeticum while undergoing standard treatment. Topical steroids were used consistently to treat these patients, and their blood test results differed from that of patients who did not use topical steroids. Patients with eczema herpeticum had significantly higher lactate dehydrogenase concentrations (600 U/L vs. $428 \mathrm{U} / \mathrm{L}$ ), but lower eosinophil (2,925/ $\mu \mathrm{L}$ vs. $7,238.1 / \mu \mathrm{L}), \mathrm{WBC}(13,948 / \mu \mathrm{L}$ vs. $26,279 / \mu \mathrm{L})$, and platelet counts $\left(438 \times 10^{3} / \mu \mathrm{L}\right.$ vs. $\left.742 \times 10^{3} / \mu \mathrm{L}\right)(P<0.05)$. Although statistically insignificant, these patients also had higher serum albumin $(3.0 \mathrm{~g} / \mathrm{dL}$ vs. $2.6 \mathrm{~g} / \mathrm{dL}$ ) and CRP (22.9 mg/L vs. $0.4 \mathrm{mg} / \mathrm{L})$ levels. Their sodium (136.3 $\mathrm{mEq} / \mathrm{L}$ vs. $129.5 \mathrm{mEq} / \mathrm{L})$ and potassium concentrations (4.75 $\mathrm{mEq} / \mathrm{L}$ vs. $5.77 \mathrm{mEq} / \mathrm{L}$ ) were within the normal range and were

Table 2. Comparison of patients who used steroids $(n=4)$ and those who declined steroid use $(n=21)$

\begin{tabular}{|c|c|c|c|}
\hline Characteristic & Steroid refusal $(n=21)$ & Use of steroid $(n=4)$ & $P$ value \\
\hline Total protein (g/dL) & $4.2 \pm 0.6$ & $4.7 \pm 0.6$ & 0.265 \\
\hline Albumin (g/dL) & $2.6 \pm 0.5$ & $3.0 \pm 0.4$ & 0.145 \\
\hline AST (U/L) & $53.7 \pm 19.2$ & $72.8 \pm 71.0$ & 0.458 \\
\hline ALT (U/L) & $39.5 \pm 16.4$ & $46.8 \pm 39.3$ & 0.711 \\
\hline LDH (U/L) & $428 \pm 256$ & $600 \pm 77$ & 0.026 \\
\hline Egg white $\left(\mathrm{kU}_{A} / \mathrm{L}\right)$ & $65.7 \pm 39.4$ & $60.7 \pm 29.6$ & 0.757 \\
\hline $\operatorname{Milk}\left(\mathrm{kU}_{\mathrm{A}} / \mathrm{L}\right)$ & $31.4 \pm 34.2$ & $33.6 \pm 46.7$ & 0.656 \\
\hline Peanut $\left(\mathrm{kU}_{\mathrm{A}} / \mathrm{L}\right)$ & $42.3 \pm 41.1$ & $43.5 \pm 34.7$ & 0.765 \\
\hline $\mathrm{Dp}\left(\mathrm{kU}_{\mathrm{A}} / \mathrm{L}\right)$ & $14.4 \pm 30.9$ & $20.9 \pm 33.4$ & 0.710 \\
\hline Sodium (mEq/L) & $129.5 \pm 7.6$ & $136.3 \pm 1.0$ & 0.037 \\
\hline Potassium (mEq/L) & $5.8 \pm 1.0$ & $4.8 \pm 0.5$ & 0.014 \\
\hline Total lgE (U/mL) & $1,450 \pm 913$ & $1,355 \pm 1,118$ & 0.910 \\
\hline Eosinophil count $(/ \mu \mathrm{L})$ & $7,238 \pm 3,911$ & $2,925 \pm 2,957$ & 0.038 \\
\hline ECP $(\mu \mathrm{g} / \mathrm{L})$ & $114 \pm 82$ & $80 \pm 84$ & 0.624 \\
\hline BUN (mg/dL) & $9.1 \pm 8.9$ & $4.8 \pm 3.1$ & 0.193 \\
\hline Creatinine (mg/dL) & $0.35 \pm 0.14$ & $0.23 \pm 0.05$ & 0.112 \\
\hline WBC $\left(\times 10^{3} / \mu \mathrm{L}\right)$ & $26,279 \pm 5,515$ & $13,948 \pm 6,398$ & 0.005 \\
\hline $\mathrm{CRP}(\mathrm{mg} / \mathrm{L})$ & $0.4 \pm 0.4$ & $22.9 \pm 38.6$ & 0.103 \\
\hline
\end{tabular}

Values are presented as mean \pm standard deviation.

AST, aspartate Transaminase; ALT, alanine Transaminase; LDH, lactate dehydrogenase; Dp, Dermatophagoides pteronyssinus; ECP, eosinophil cationic protein; BUN, blood urea nitrogen; WBC, white blood cell; CRP, C-reactive protein. 
Table 3. Allergy laboratory test results of patients

\begin{tabular}{lc}
\hline Characteristic & Value \\
\hline Total lgE $(\mathrm{U} / \mathrm{mL})$ & $1,864(127-3,000)$ \\
Specific $\operatorname{lgE}\left(\mathrm{KU} \mathrm{A}_{\mathrm{A}} / \mathrm{L}\right)$ & $76.5(0-100)$ \\
Egg white & $20.5(0-100)$ \\
Milk & $30(0-100)$ \\
Peanut & $0.77(0-100)$ \\
HDM & $5,810(20-17,130)$ \\
Eosinophil $(\mu \mathrm{L})$ & $93.45(2-200)$ \\
ECP $(\mu \mathrm{g} / \mathrm{L})$ &
\end{tabular}

Values are presented as median (range).

HDM, house dust mite; ECP, eosinophil cationic protein.

Table 4. Patient laboratory data

\begin{tabular}{lc}
\hline Characteristic & Value \\
\hline Skin culture & \\
S. aureus & $20(76.9)$ \\
MRSA & $6(23.1)$ \\
CNS & $2(7.7)$ \\
Negative & $4(15.4)$ \\
WBC $\left(10^{3} / \mu \mathrm{L}\right)$ & $24,280(8,380-37,530)$ \\
$\mathrm{PLT}\left(10^{3} / \mathrm{LL}\right)$ & $6,665(223-1,312)$ \\
$\mathrm{TP}(\mathrm{g} / \mathrm{dL})$ & $4.3(3.2-5.6)$ \\
Albumin $(\mathrm{g} / \mathrm{dL})$ & $2.7(1.7-3.4)$ \\
$\mathrm{Na}^{+}(\mathrm{mEg} / \mathrm{L})$ & $132(112-141)$ \\
$\mathrm{K}^{+}(\mathrm{mEq} / \mathrm{L})$ & $5.4(4.2-9.3)$ \\
\hline
\end{tabular}

Values are presented as number (\%) or median (range).

S. aureus, Staphylococcus aureus; MRSA, methicillin-resistant Staphylococcus aureus; CNS, coagulase-negative staphylococci; WBC, white blood cell; PLT, platelet; TP, total protein.

statistically significant $(P<0.05)$ (Table 2$)$.

Table 3 shows the median laboratory values for each patient. The median values for all patients were as follows: total IgE, 1,864 U/ $\mathrm{mL}$ (range, 127-3,000 U/mL); specific IgE for egg whites, $76.5 \mathrm{kU}_{\mathrm{A}} /$

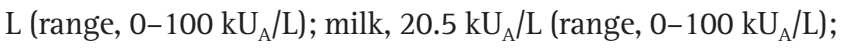
and peanuts, $30 \mathrm{kU}_{\mathrm{A}} / \mathrm{L}$ (range, $0-100 \mathrm{kU}_{\mathrm{A}} / \mathrm{L}$ ). Twenty-five patients (96.2\%) had egg white sensitization ( $\left.>0.35 \mathrm{kU}_{\mathrm{A}} / \mathrm{L}\right), 24$ had milk sensitization (92.3\%), and 24 had peanut sensitization (92.3\%). Specific IgE for Dp was $0.77 \mathrm{kU}_{\mathrm{A}} / \mathrm{L}$ (range, 0-100) and 21 patients had sensitization (76.9\%). The enrolled participants were instructed to avoid foods containing potential allergens. The median eosinophil count was 5,810/ $\mu \mathrm{L}$ (range, 20-17,130/ $\mu \mathrm{L}$ ), which far exceeded the cutoff for eosinophilia $(400 / \mu \mathrm{L})$, and this consequently increased the WBC counts. Additionally, ECP was above normal $(15 \mu \mathrm{g} / \mathrm{L})$ at $93.45 \mu \mathrm{g} / \mathrm{L}$ (range, 2-200 $\mu \mathrm{g} / \mathrm{L}$ ).

The laboratory data of all patients are shown in Table 4. The median WBC count of all patients was $24,280 \times 10^{3} / \mu \mathrm{L}$ and the median platelet count was $6,665 \times 10^{3} / \mu \mathrm{L}$ (range, 223-1,312/ $\mathrm{LL}$ ). The median serum albumin and total protein levels were low at $2.7 \mathrm{~g} / \mathrm{dL}$ (range,
$1.7-3.4 \mathrm{~g} / \mathrm{dL}$ ) and $4.3 \mathrm{~g} / \mathrm{dL}$ (range, 3.2-5.6 g/dL), respectively. The median serum sodium concentration was $132 \mathrm{mEq} / \mathrm{L}$ (range, 112$141 \mathrm{mEq} / \mathrm{L})$, and 10 patients (38.5\%) had hyponatremia (<130 mEq/ L). The median serum potassium concentration was $5.4 \mathrm{mEq} / \mathrm{L}$ (range, 4.2-9.3 $\mathrm{mEq} / \mathrm{L}$ ), and 12 patients (46.2\%) had hyperkalemia ( $>5.5 \mathrm{mEq} / \mathrm{L}$ ). Regarding the results of skin cultures, $S$. aureus was confirmed in 20 patients (76.9\%), 6 of whom (23.1\%) had methicillin-resistant $S$. aureus.

Table 5 shows the treatment regimen used in all patients. All patients received systemic antibiotics. Second-generation cephalosporin (cefuroxime) was administered to 7 patients, third-generation cephalosporin (cefotaxime, cefixime) to 17 patients, and a macrolide (roxithromycin) to 2 patients. The length of hospital stay was not significantly related to the type of antibiotics used $(P=0.906)$. Regarding steroid ointment, 24 patients (92.3\%) used group 5 prednicarbate (Dermatop), and 1 patient (3.8\%) used hydrocortisone valerate (Westcort). One patient (3.8\%) did not use a steroid ointment due to eczema herpeticum and ecthymagangrenosum. The length of hospital stay was also not significantly related to steroid ointment use $(P=0.462){ }^{6}{ }^{6}$ Of the 5 patients with eczema herpeticum in the present study, 1 patient did not use a steroid ointment, and eczema herpeticum did not worsen when steroid ointment was used. We consider that this occurred because both antiviral agents and antibiotics were used for treatment. Although there are varying opinions regarding the application of steroids in eczema herpeticum, one study demonstrated that topical application does not prolong disease duration or generate poor outcomes."

In our study, only 3 of 5 patients with eczema herpeticum tested positive for $S$. aureus on skin culture, which is in contrast to a previous report suggesting that $S$. aureus is an important cause of eczema herpeticum. Hence, there appears to be a mechanism that plays a greater role in destroying the skin barrier and facilitating protein loss in eczema herpeticum than S. aureus.

Twelve patients (46.2\%) used an antiviral agents (acyclovir). Acyclovir was used prophylactically in these 12 patients as they suffered from fever or presented with oozing which may be a symptom of undiagnosed eczema herpeticum. The antiviral agent was administered twice a day intravenously for at least 1 hour per session at a dose of $500 \mathrm{mg} / \mathrm{m}^{2}$ for between 5 and 7 days. The length of hospital stay was not significantly related to the use of antiviral agents $(P=0.980)$. Eight patients (30.8\%) underwent electrolyte correction due to hyponatremia or hyperkalemia. Of these, 1 patient (3.8\%) received IV calcium gluconate due to an electrocardiogram abnormality and a risk of cardiac arrest due to hyperkalemia. The length of hospital stay was not significantly related to electrolyte correction $(P=0.765)$. Four patients $(15.4 \%)$ received IV albumin. The length of hospital stay was not significantly related to albumin administration $(P=0.352)$. Although albumin concentration increased immediately on IV administration, 7 of 22 patients (31.8\%) who did not receive IV albumin showed a decreased albumin level during 


\begin{tabular}{|c|c|c|c|c|c|c|}
\hline No & Hospitalization days & Systemic antibiotics & Steroid ointment & Acyclovir & Electrolyte correction & Albumin infusion \\
\hline 1 & 12 & $\vee$ & $\vee$ & & & \\
\hline 2 & 13 & $\vee$ & $\vee$ & & & \\
\hline 3 & 14 & $\vee$ & & $\vee$ & & \\
\hline 4 & 13 & $\vee$ & $\vee$ & $\vee$ & & \\
\hline 5 & 16 & $\vee$ & $\vee$ & & $\vee$ & \\
\hline 6 & 11 & $\vee$ & $\vee$ & $\vee$ & & \\
\hline 7 & 17 & $\vee$ & $\vee$ & & $\vee$ Calcium gluconate & \\
\hline 8 & 10 & $\vee$ & $\vee$ & & & $\vee$ \\
\hline 9 & 14 & $\vee$ & $\vee$ & & & \\
\hline 10 & 9 & $\vee$ & $\vee$ & & & \\
\hline 11 & 9 & $\vee$ & $\vee$ & & & \\
\hline 12 & 11 & $\vee$ & $\vee$ & $\vee$ & & \\
\hline 13 & 14 & $\vee$ & $\vee$ & $\vee$ & $\vee$ & \\
\hline 14 & 16 & $\vee$ & $\vee$ & $\vee$ & & \\
\hline 15 & 14 & $\vee$ & $\vee$ & & & \\
\hline 16 & 12 & $\vee$ & $\vee$ & $\vee$ & & \\
\hline 17 & 10 & $\vee$ & $\vee$ & & $\vee$ & \\
\hline 18 & 9 & $\vee$ & $\vee$ & $\vee$ & $\vee$ & $\vee$ \\
\hline 19 & 6 & $\vee$ & $\vee$ & $\vee$ & & \\
\hline 20 & 10 & $\vee$ & $\vee$ & & $\vee$ & \\
\hline 21 & 10 & $\vee$ & $\vee$ & & & \\
\hline 22 & 14 & $\vee$ & $\vee$ & $\vee$ & & \\
\hline 23 & 13 & $\vee$ & $\vee$ & $\vee$ & $\vee$ & V \\
\hline 24 & 7 & V & V & V & & \\
\hline 25 & 7 & $\vee$ & $\vee$ & & $\vee$ & \\
\hline 26 & 10 & $\vee$ & $\vee$ & & & V \\
\hline
\end{tabular}

their hospital stay. There were no patients with serious symptoms due to albumin reduction, and albumin concentration recovered to $>3.5 \mathrm{~g} / \mathrm{dL}$ in 8 of 10 patients.

\section{Discussion}

Atopic dermatitis with hypoproteinemia is frequently accompanied by hyponatremia, hyperkalemia, hypogammaglobulinemia, elevated renin and aldosterone levels, and growth retardation. ${ }^{9)}$ In most reports on atopic dermatitis, the patients have been predominantly boys (92.3\%). All 6 cases reported in the United States in 1999 involved boys, ${ }^{10)}$ and the 2 cases reported in Japan in 2001 also involved boys. ${ }^{11)}$ Furthermore, 5 of 6 cases reported in Kyoto, Japan in 2006, were boys ${ }^{12)}$; however, this propensity for the disease to manifest in boys remains unknown. Genetic factors may play a role; therefore, additional studies are needed. Although most reported cases have been accompanied with growth or developmental disorders, the incidences of failure to thrive (26.9\%) and developmental disorders (7.7\%) were low in this study. This may be due to selection bias, as case reports usually involve cases of high severity or serious complications. ${ }^{13)}$ We consider that the higher prevalence among infants aged $<1$ year may be due to the greater presence of moisture or protein leakage through the skin due to an inadequate skin barrier compared to older children. Here, eczema and skin lesions usually affected the face, which is in line with the age-specific features of atopic dermatitis. Aural discharge or otitis externa (23.1\%) and blepharitis or keratoconjunctivitis (26.9\%) occurred frequently, and these conditions promote protein leakage. In our study, parents' allergic history or a cesarean section delivery did not affect the incidence of atopic dermatitis with hypoproteinemia.

Reports differ concerning the causes of hypoproteinemia. First, hypoproteinemia is known to be due to protein leakage through severe skin lesions, dietary restrictions due to multiple food allergies, and malnutrition. ${ }^{10)}$ Previously, protein leakage through the intestine was believed to be a cause of hypoproteinemia as patients showed digestive symptoms; however, a study that compared fecal and skin lesion exudates confirmed that protein loss occurs through the skin. ${ }^{2)}$ Allergic skin inflammations and superantigens produced 
by $S$. aureus damage the skin barrier, thereby worsening protein leakage. ${ }^{3)}$ In our study, the percentage of patients positive for $S$. aureus (76.9\%) was lower than in Nomura's report (100\%). However, protein leakage appears to have occurred, as patients had broad and severe skin lesions with high SCORAD indices. Future studies should investigate the effects of superantigens on the development of hypoproteinemia. In another report, ten of 15 patients (66.7\%) were positive for $S$. aureus superantigen.$^{14)}$ Furthermore, one report suggested that atopic dermatitis with hypoproteinemia and eosinophilia was associated with considerably elevated CD69, EDN, and IL-18 levels; however, IL-4, IL-5, and IL-12 levels were comparable to that of atopic dermatitis with normoproteinemia. It has been suggested that the surface proliferation of CD69 in eosinophils provides a valuable clue in identifying the pathogenesis of hypoproteinemia. ${ }^{15)}$ We also found high levels of eosinophilia and ECP in our study, which suggest that an eosinophil-based mechanism is involved. Declining to apply topical steroids, as well as eczema herpeticum were suspected to be important factors in the development of hypoproteinemia. Not applying topical steroids due to a fear of steroids, as well as inappropriate skin care, the use of folk remedies, and traditional Korean medical therapies have been persumed to be important causes of hypoproteinemia resulting from protein leakage. Steroid phobia is reported to be a global phenomenon that exacerbates atopic dermatitis. ${ }^{16)}$ Approximately $67.5 \%$ of all atopic dermatitis patients in South Korea are reported to be steroid phobic, and this phobia worsens as the patient's condition deteriorates and when they become aware of the possible side effects of steroid use. ${ }^{17)}$ Therefore, many patients resort to alternative therapies, such as folk remedies and traditional Korean medical therapies, to try and avoid steroids as much as possible. The high incidence of hypoproteinemia due to declining to apply topical steroids $(n=21,80.8 \%)$ is a stark warning of the danger of such poorly evidenced treatment choices. In Italy, a 15-day-old newborn with atopic dermatitis developed life-threatening hypoproteinemia because the infant was fed rice, vegetables, sunflower oil, and apple, and topical steroids were not applied. ${ }^{18)}$ In Japan, a patient who relied heavily on prune juice without using topical steroids developed hypoproteinemia as a result of an absorption disorder caused by diarrhea, protein leakage through the skin, and malnutrition. ${ }^{11)}$ According to another report, herbal medicine itself caused lymphocyte stimulation, thereby leading to hypoproteinemia; therefore, herbal mediciens should be used with caution. In particular, extra care should be taken for infants aged $<1$ year. ${ }^{19)}$

Finally, hypoproteinemia may be associated with eczema herpeticum. With herpes infection, skin conditions may worsen rapidly, and hypoproteinemia appears to be due to protein leakage.

In our study, patients with eczema herpeticum rarely had electrolyte abnormalities, eosinophilia, or thrombocytosis. ${ }^{20)}$ Eczema herpeticum frequently affects adolescents and young adults in their 20s, and we suspect that infants aged $\leq 12$ months have an inadequate skin barrier, which increases their risk for hypoproteinemia. ${ }^{21,22)}$ Eczema herpeticum increases biomarkers related to Th2 helper cells, increases the eosinophil count and specific IgE levels, and induces antigen sensitization; therefore, no marked differences were observed in the allergy test results. ${ }^{23,24)}$

\section{Comparison of treatments}

The length of hospital stay was not significantly related to the use of antibiotics or antiviral agents. IV albumin infusion also had no significant effect on hospital stays. Some patients who did not receive albumin infusions presented with progressive albumin reduction; however, no particularly dangerous symptoms were present and, in most patients, the albumin levels returned to normal after 10 days without reduction. Only 2 patients (7.7\%) did not achieve a normal range after 10 days, and 2 patients (7.7\%) were lost to follow-up. Serious symptoms due to a worsening general status were not observed in our study, and albumin administration had no marked effects on treatment progress. ${ }^{14)}$ Electrolyte abnormality was common, but rarely life-threatening. In our study, only one patient received emergency treatment for arrhythmia due to hyperkalemia. Electrolytes were quickly balanced through adjusting fluid composition, and electrolyte control did not affect treatment progress.

\section{Limitations of this study}

First, follow-up was difficult because the study population had a general corticosteroid phobia and the use of topical steroids as a standard treatment had been declined. Although we attempted to follow up on the long-term changes in the severity of atopic dermatitis, food allergies, bronchial asthma, and rhinitis, only 7 patients (26.9\%) could be followed up for $>6$ months.

Second, the treatment protocols were inconsistent. Various treatments, including antibiotics, antiviral agents, albumin supplementation, and electrolyte control, were used depending on the patient's status. Because our data were based on medical records over the past 10 years, an observer bias may have also existed.

Third, treatment outcomes were compared simply based on the length of hospital stay. We could not compare the changes in the SCORAD index or in blood test results relating to the various treatment modalities.

Nevertheless, we anticipate that our findings will provide some clues to understanding the etiology, as well as tests and treatments, concerning atopic dermatitis with hypoproteinemia.

In conclusion, atopic dermatitis with hypoproteinemia frequently affects male infants aged $<1$ year, and may result from parents or caregivers declining to apply topical steroid therapy due to steroid phobia or the onset of eczema herpeticum. Atopic dermatitis with hypoproteinemia is commonly accompanied with aural discharge and keratoconjunctivitis, and growth retardation may also be present. If no serious symptoms are observed, albumin and electrolyte ab- 
normalities tend to improve gradually even without treatment. Additional studies are needed to investigate hypoproteinemia with eczema herpeticum, which can rapidly worsen and may involve a different pathophysiology than atopic dermatitis.

\section{Conflicts of interest}

No potential conflict of interest relevant to this article was reported.

\section{References}

1. Abrahamov A, Schifmann R, Goldstein R, Tal Y, Freier S. Growth failure due to protein loss in dermatitis. Eur J Pediatr 1986;145:223-6.

2. Lee C, Lee S, Kim SW, Sung M. Clinical significance of atopic dermatitis with hypoalbuminemia in Korean children. Iran J Pediatr 2017; 27:e7702.

3. Nomura I, Katsunuma T, Tomikawa M, Shibata A, Kawahara H, Ohya Y, et al. Hypoproteinemia in severe childhood atopic dermatitis: a serious complication. Pediatr Allergy Immunol 2002;13:287-94.

4. Hanifin JM, Rajka G. Diagnostic features of atopic dermatitis. Acta Derm Venereol (Stockh) Suppl 1980;92:44-7.

5. Korea Centers for Disease Control and Prevention, Division of Chronic Disease Surveillance, Committee for the Development of Growth Standard for Korean Children and Adolescents; Korean Pediatric Society, Committee for School Health and Public Health Statistics. 2007 Korean children and adolescents growth standard (commentary for the development of 2007 growth chart). Cheongju (Korea): Korea Centers for Disease Control and Prevention, Division of Chronic Disease Surveillance, 2007.

6. Stoughton RB. Vasoconstrictor assay - specific applications. In: Maibach HI, Surber C. Topical corticosteroids. Basel: Karger Publishers, 1992:42-53.

7. Aronson PL, Shah SS, Mohamad Z, Yan AC. Topical corticosteroids and hospital length of stay in children with eczema herpeticum. Pediatr Dermatol 2013;30:215-21.

8. Kimata H. Rapidly increasing incidence of Kaposi's varicelliform eruption in patients with atopic dermatitis. Indian J Dermatol Venereol Leprol 2008;74:260-1.

9. Shinagawa T, Matsuda S, Ishiguro H, Shikada M, Takakura I, Morimoto $\mathrm{T}$, et al. Hyperaldosteronemia and hypogammaglobulinemia secondary to atopic dermatitis-induced exudation in an infant pre- senting with growth failure. Tokai J Exp Clin Med 2007;32:18-22.

10. Terada A, Fujisawa T, Iguchi K, Kamiya H. Six cases of severe atopic dermatitis with hypoalbuminemia. Jpn J Pediatr Allergy Clin Immunol 1999;13:38-42.

11. Watanabe M, Kawahara K, Ohara A, Tominaga A, Yanagawa S, Okamoto N, et al. Over consumption with prune juice as a folk medicine in two infants with severe atopic dermatitis with hypoproteinemia. Jpn J Pediatr Allergy Clin Immunol 2001;15:540-5.

12. Katoh N, Hosoi H, Sugimoto T, Kishimoto S. Features and prognoses of infantile patients with atopic dermatitis hospitalized for severe complications. J Dermatol 2006;33:827-32.

13. Yagi Y, Yagi Y, Sageshima H, Yoshizaki M. A case of severe atopic dermatitis with hypoalbuminemia and failure to thrive. Jpn J Pediatr Allergy Clin Immunol 2002;16:221-5.

14. Akashi M, Nomura I, Saito A, Narita M, Suda T, Akasawa A, et al. Clinical features of severe infant atopic dermatitis with hypoproteinemia. Arerugi 2008;57:853-61.

15. Toma T, Mizuno K, Okamoto H, Kanegane C, Ohta K, Ikawa Y, et al. Expansion of activated eosinophils in infants with severe atopic dermatitis. Pediatr Int 2005;47:32-8.

16. Aubert-Wastiaux H, Moret L, Le Rhun A, Fontenoy AM, Nguyen JM, Leux C, et al. Topical corticosteroid phobia in atopic dermatitis: a study of its nature, origins and frequency. Br J Dermatol 2011;165: 808-14.

17. Lee JY, Her Y, Kim CW, Kim SS. Topical corticosteroid phobia among parents of children with atopic eczema in Korea. Ann Dermatol 2015; 27:499-506.

18. Novembre E, Leo G, Cianferoni A, Bernardini R, Pucci N, Vierucci A. Severe hypoproteinemia in infant with AD. Allergy 2003;58:88-9.

19. Yasutomi M, Okazaki S, Kawakita A, Hayashi H, Murai H, Mayumi M, et al. Case of atopic dermatitis in infant treated with Chinese herbal medicines and nsaids ointment, which induced weight loss, electrolyte disturbance and hypoproteinemia. Arerugi 2013;62:827-32.

20. Wang AS, Liang MG, Schneider LC. Severe atopic dermatitis and transient hypogammaglobulinemia in children. Pediatr Dermatol 2012;29:73-8.

21. Bork K, Bräuninger W. Increasing incidence of eczema herpeticum: analysis of seventy-five cases. J Am Acad Dermatol 1988;19:1024-9.

22. Wollenberg A, Zoch C, Wetzel S, Plewig G, Przybilla B. Predisposing factors and clinical features of eczema herpeticum: a retrospective analysis of 100 cases. J Am Acad Dermatol 2003;49:198-205.

23. Leung DY. Why is eczema herpeticum unexpectedly rare? Antiviral Res 2013;98:153-7.

24. Beck LA, Boguniewicz M, Hata T, Schneider LC, Hanifin J, Gallo R, et al. Phenotype of atopic dermatitis subjects with a history of eczema herpeticum. J Allergy Clin Immunol 2009;124:260-9, 269.e1-7. 